\title{
MESENTERIC LYMPHANGIOMA AS A CAUSE OF ACUTE ABDOMINAL SYMPTOMS
}

\author{
BY \\ M. LEVENE, P. A. WALKER and T. A. WHITE \\ From the Christie Hospital, Manchester, St. Richards Hospital, Chichester, and Withington and Altrincham \\ Hospitals
}

(RECEIVED FOR PUBLICATION JUNE 27, 1956)

Lymphangiomata of the abdominal organs are so rare that they are hardly considered in the differential diagnosis of the acute abdomen. The following two cases, however, presented as surgical emergencies and it is felt that they may be of some general interest.

\section{Case Reports}

Case 1. E.S., a 12-year-old boy, was admitted to Altrincham General Hospital on June 29, 1953. He gave a 24-hour history of intermittent colicky lower abdominal pain, coming at half-hourly intervals, without vomiting. The bowels had moved in this period and flatus was passed during the examination. The temperature was $98^{\circ} \mathrm{F}$., pulse 88, respiration 20 . A tense dull mass was felt in the lower abdomen, more on the left than on the right. Peristalsis was brisk.

The differential diagnosis lay between (1) partial obstruction, associated with volvulus, either from adhesions following appendicectomy two years previously, mesenteric adenitis, congenital bands, or other mesenteric abnormality, or simply due to an impacted foreign body; (2) an acute retroperitoneal lesion such as haematoma, perinephric abscess, or a rapidly growing tumour.

At laparotomy two days later a multilocular cystic mass was removed from the mesentery of the lower ileum together with the overlying bowel, and end-to-end anastomosis was performed. The patient made an uneventful recovery and has remained well.

Pathological Examination. The specimen (Figs. 1 and 2) was received partly dissected and opened. It measured $16 \times 15 \times 7 \mathrm{~cm}$. and consisted of $35 \mathrm{~cm}$. of small bowel with the associated segment of mesentery greatly expanded and distorted to form an irregular lobulated cystic mass $12 \times 12 \times 7 \mathrm{~cm}$. overall.

In places the cysts stopped short of the bowel: elsewhere they reached it and the mesentery was pushed outwards and upwards so that the bowel was partly surrounded.

The cysts varied in size from minute up to $5 \mathrm{~cm}$. across. Some contained fluid, some gelatinous material. Most of the cysts walls were under $0.2 \mathrm{~cm}$. in thickness but there were a few solid regions from 0.5 to $1 \mathrm{~cm}$. across. Some of the larger cysts were trabeculated, and except for a few small areas of haemorrhage and fibrin deposition, the walls were smooth and glistening throughout.

The margins of the cystic area blended into the surrounding mesentery, but excision appeared complete.

Histology. Sections show many spaces of varying size, some containing pink albuminous material (Fig. 3). Some have no definite lining, others are lined by inconspicuous flattened cells, apparently endothelial in nature (Fig. 4). They are situated in a very loose connective tissue containing some fat and in one section considerable quantities of smooth muscle (Fig. 5). The blood capillaries show no unusual features, but small, empty, presumably lymphatic, spaces are numerous. Some small aggregations of lymphocytes are present, and in a few places a layer of lymphocytes is grouped under a cyst wall (Fig. 6). In addition small numbers of lymphocytes, eosinophils and plasma cells are scattered throughout the stroma while some areas show more acute inflammation and small haemorrhages.

The submucosa of the small bowel in the section is thickened and oedematous.

No ectopic bowel epithelium is seen. There is no evidence of malignancy. The condition is considered to be of lymphangiomatous nature.

Case 2. D.W., a boy, aged 4 years, was admitted to Manchester Northern Hospital complaining of lower abdominal pains. There had been malaise for two days but no vomiting or nausea.

Examination showed a well developed youngster. The temperature was $102^{\circ} \mathrm{F}$., pulse 120 , respiration 24 . The tongue was moist. There was a localized, tender, smooth mass in the right iliac fossa extending to the rectus. A diagnosis of appendix abscess was made. Laparotomy on the same day revealed a large cystic tumour. A right hemicolectomy was performed and the child made an uneventful recovery, being discharged three weeks after the operation. He has remained well to date.

Macroscopic Appearance. The specimen consists of $9 \mathrm{~cm}$. of ileum and $8 \mathrm{~cm}$. of caecum and ascending colon, with the appendix lying infero-medially (Fig. 7). Partly 


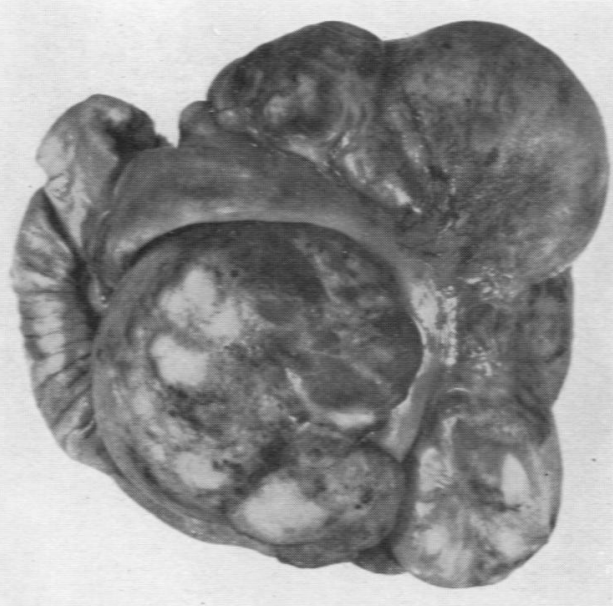

\begin{tabular}{llllll|l|l|l|l|llll}
\hline$x$ & 2 & 3 & 4 & 5 & 6 & 7 & 8 & 9 & 10 & 11 & 12 & 13 & 14
\end{tabular}

Fig. 1.-General view of the specimen.

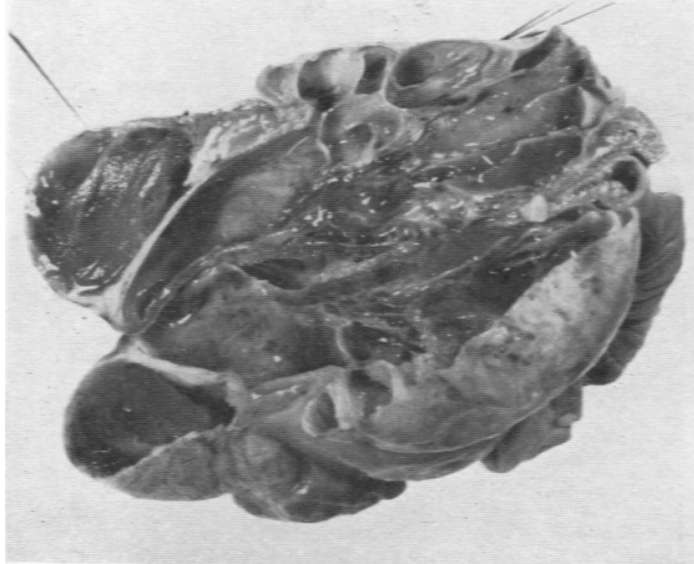

Fig. 2-Cross section of the specimen.

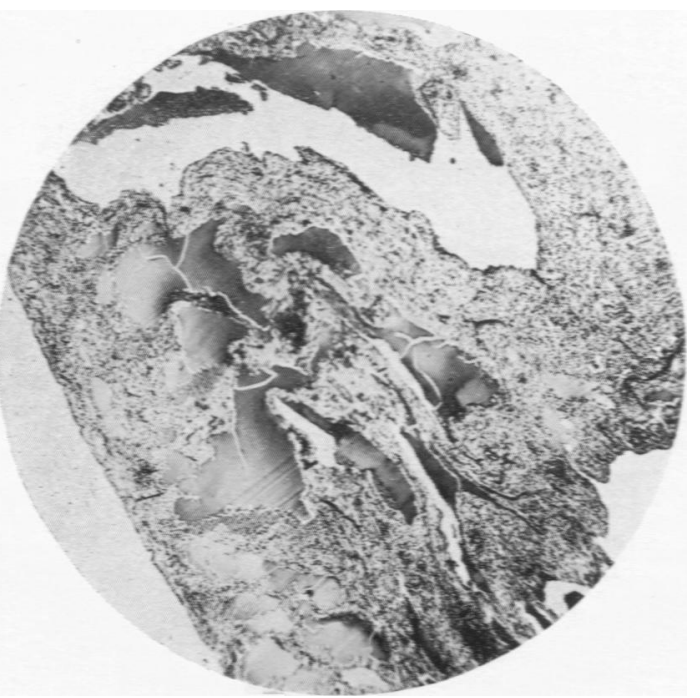

Fig. 5.-Typical area of tumour $(\times 25)$.

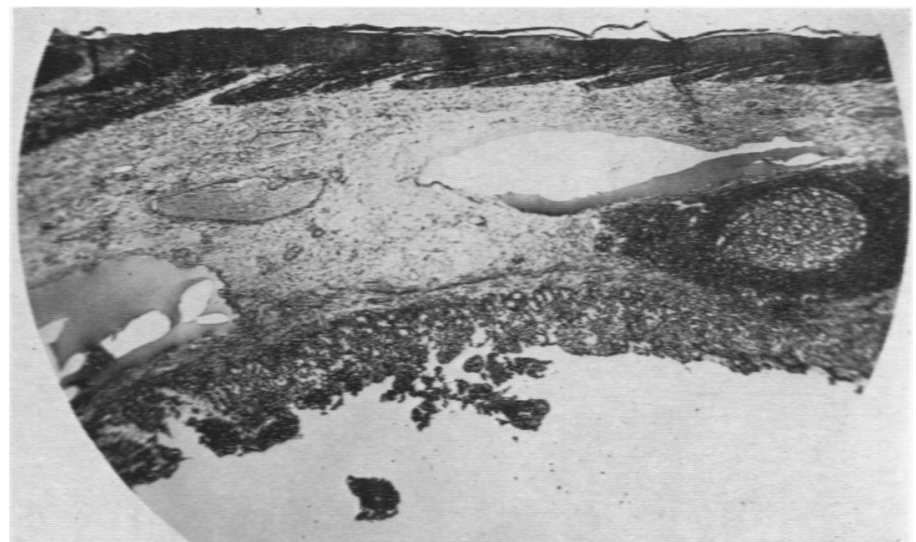

Fig. 3.-Cysts in the bowel wall $(x 30)$.

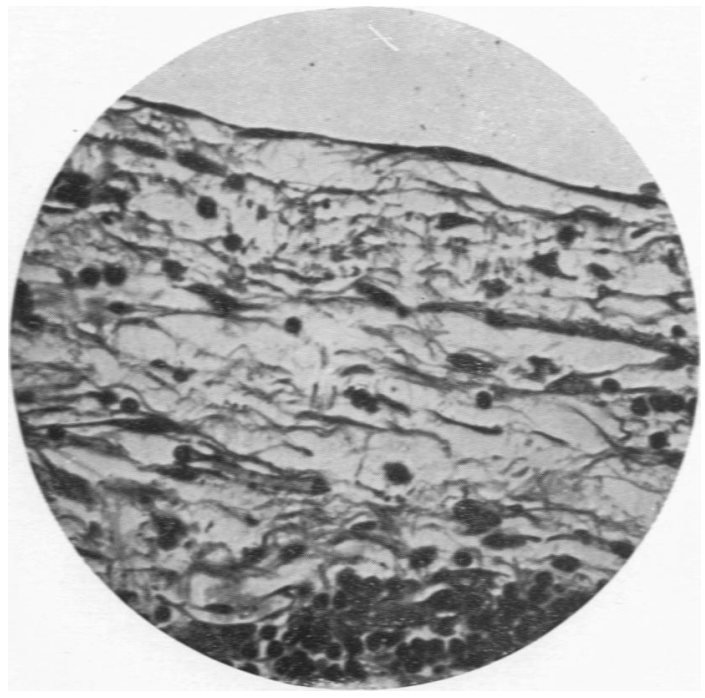

Fig. 4.-Part of the cyst wall showing endothelium ( $\times 350)$.

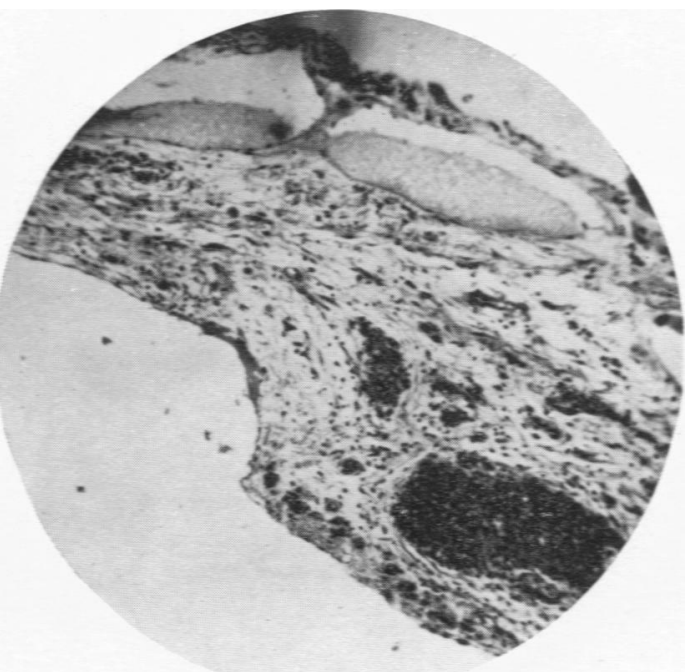

Fig. 6.-General structure and lymphoid aggregations $(\times 90)$. 


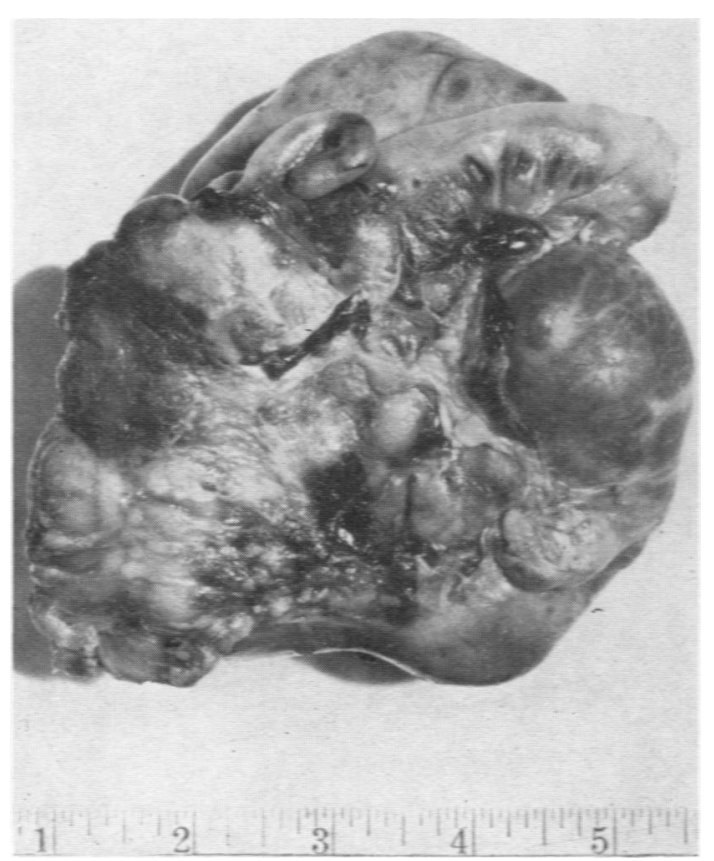

Fig. 7.

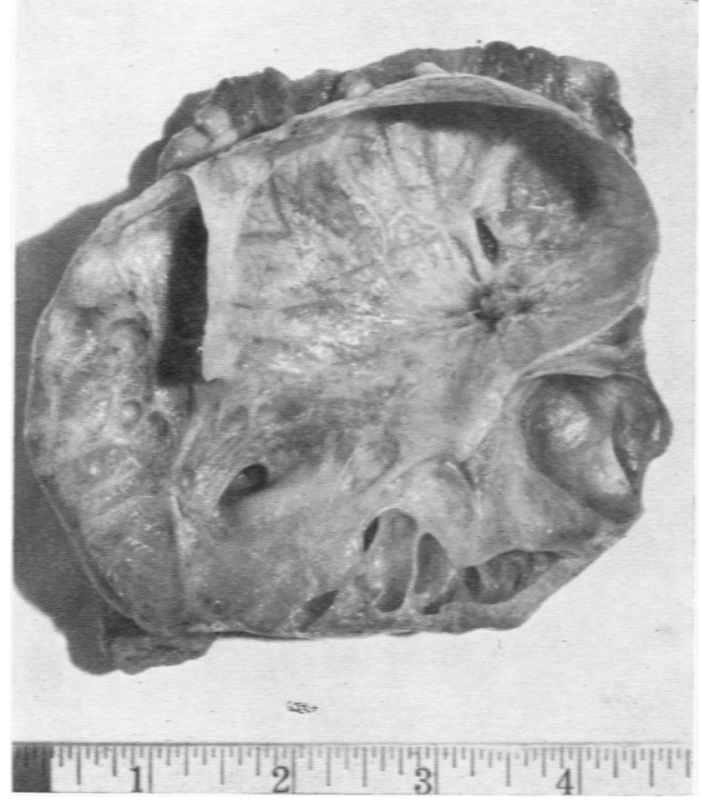

Fig. 8.

Fig. 7.-Cyst from the posterior aspect. Fig. 8.-Opened cyst.

Fig. 9.- Solid part of the cyst $(\times 20)$.

Fig. 10.-Part of cyst wall ( $x$ 350).

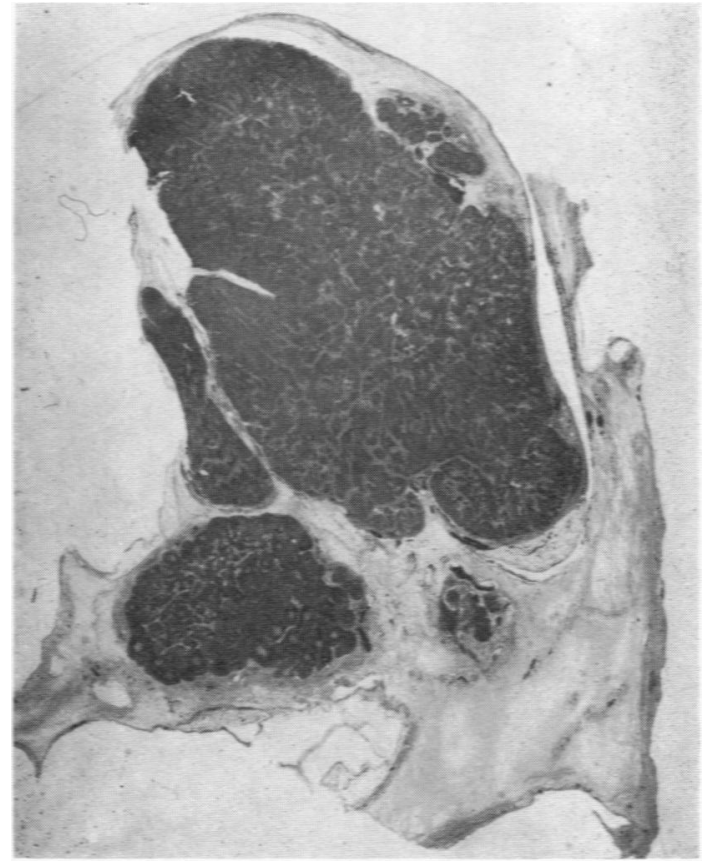

FK. 9.

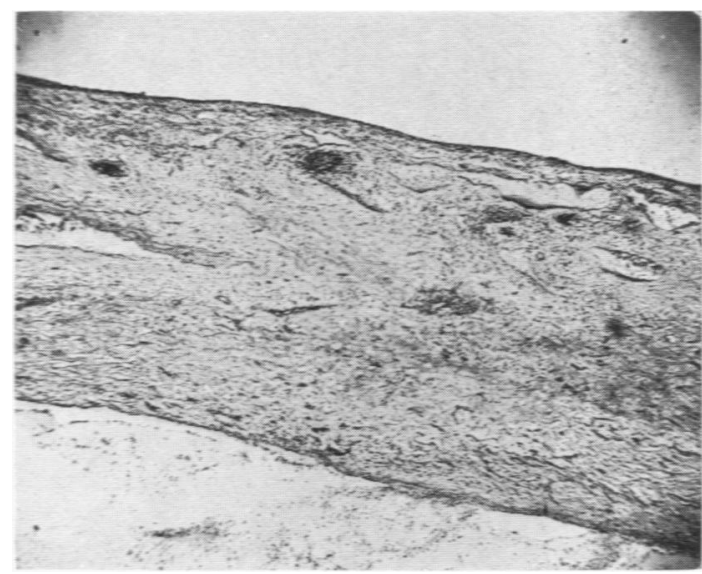

FK. 10.

in the mesentery of the terminal ileum and continuing into the adjacent folds of peritoneum at the medial border of the caecum is a cystic swelling measuring $13 \times 10 \times 5 \mathrm{~cm}$. This consists of four main loculi and numerous smaller compartments (Fig. 8). The outer surface is smooth and completely covered by peritoneum in which is a little fat. The inner lining is smooth and somewhat trabeculated with no evidence of haemorrhage. At one point is a solid pink area, $3 \times 3 \times 2 \mathrm{~cm}$., of similar consistency to five lymph nodes which lie on the posterior aspect. 
Microscopic Examination. Sections were taken from various parts of the cyst walls from the solid portions and from the ascending colon, ileum, caecum and lymph nodes. The cysts show an endothelial lining with aggregations of lymphoid tissue especially in the solid part (Fig. 9). The softer parts are honeycombed with spaces lined by endothelium. The diagnosis is considered to be a cavernous lymphangioma. There is no evidence of malignancy.

\section{Discussion}

Lymphangiomata of the mesentery are rare. After an extensive survey of the literature Warfield (1932) found that mesenteric cysts were the least common of abdominal tumours and commented that they were hardly mentioned in many standard works, a statement which is still largely true. He concluded moreover that of the 129 reports of mesenteric tumours available to him between 1920 and 1932 only a few were lymphangiomata. Raiford (1932) found only one lymphangioma of the abdominal viscera in 11,500 necropsies. Anatomically the condition is related to the cavernous lymphangiomata but its exact nature, like that of angiomatous malformation generally, has caused much speculation. The simple dilatation of normal channels by fibrous obstruction following inflammation does not appear adequate and it is generally agreed now that the condition is an abnormal production of lymphatic vessels, the discussion resting between those who hold it to be a true progressive neoplasm and those who consider it part of a congenital malformation. Evidence has been produced by Goetsch (1938) that the commoner cystic hygromata of the neck and axillae are true progressive neoplasms, budding off new channels which infiltrate locally, and in fact showing a low-grade malignancy. Willis (1953), however, does not accept this interpretation of Goetsch's photomicrographs. The behaviour of the mesenteric tumours and many other angiomatous conditions is perhaps more what would be expected from a congenital malformation-a local deformity or excess of lymphatic vascular tissue of the nature of a hamartoma. Most of the cases occur in childhood, but a few, for example that recently described by Colditz (1951), in later life.

Many are found incidentally and seem quiescent: others either present suddenly or at the most are known to have been developing over a short period. In spite of this apparent quick growth malignant change or spread beyond the tissue originally involved is exceedingly uncommon so that local resection usually produces a cure. It seems likely that these rapid developments are due to a dilatation of congenital anomalies following torsion, inflammation or changes in pressure such as may easily occur in so fluid a region as the abdomen. The acute onset in both the cases described here and the recent inflammation in Case 1 seem consistent with this view, which would also account for the absence of any mass of appreciable size in Case 1 at the previous appendicectomy.

\section{Summary}

Two cases of abdominal lymphangioma are reported, each presenting as an abdominal emergency in childhood.

The pathological nature of the tumour is described and comments are made on its incidence, aetiology and behaviour.

We wish to thank Mr. N. Godfrey and Mr. H. Simmons for permission to publish their cases and Dr. L. Stent, Dr. J. Davson and Dr. Russell for their advice and encourageinent.

\section{BIBLIOGRAPHY}

Beller, A. J. and Nach, R. L. (1950). Ann. Surg., 132. 287.

Colditz, P. (1951). Zbl. Chir., 76. 1530.

Ewing, J. (1940). Neoplastic Diseases, 4th ed. Philadelphia and London.

Goetsch, E. (1938). Arch. Surg. (Chicago), 36, 394.

Grausman, P. M. and Jaffe, H. L. (1928). Ann. Surg., 87, 66.

Lahey, F. H. and Eckerson. E. B. (1934). Ibid., 100. 231.

MacNab, I. and Menzies, T. (1950). Brit. J. Surg., 37, 294.

Peterson, E. W. (1932). Ann. Surg., 96, 340.

Raiford, T. S. (1932). Arch. Surg. (Chicago), 25, 122.

Warfield, J. O. (1932). Ann. Surg., 96. 329.

Willis, R. A. (1953). Pathology of Tumours, 2nd ed. London. Wood. K. (1955). Brit. J. Surg., 43, 304. 